\title{
The External Migrations in Macedonia during the Transition Period and Today
}

\author{
PhD. Stevan Aleksovski
}

Ma. Ognen Aleksoski

Ma. Oliver Cackov

\section{Doi:10.5901/mjss.2015.v6n3s2p672}

\begin{abstract}
Research in the area of migration policy is necessary to consider the various reasons for the resettlement of migrants such as economic, social, political and other. Emigrations as phenomenon are negative thing for the country because they cause adverse effects (aging society, brain drain). The total number of citizens of Republic Macedonia in the European and overseas countries could be approximated to 275,000 persons, but concerns the data that that on average from Macedonia are moving out 10,000 people. The detection of the reasons for which the emigrants leave from Macedonia and do not come back, indicates on the need to improve the living conditions in the country and on other preventive actions to prevent the proliferation of number of migrants.
\end{abstract}

Keywords: Migration, immigration, emigration, the population census, regional origin of migrants, demographic and socioeconimic characteristics, urban and rural areas, age, education, returnees, research, chi-square test.

\section{Introduction}

Migration Statistics is tasked to study the mechanical movement of the population, or migration movements.

Migrations can be external (movement, change in place of living and moving beyond national borders) and internal ( change of the place of residence within the state borders).

When choosing this very topic for treatment especially decisive influence had the great meaning of the external migration as a negative phenomenon which influents the general socioeconomic position in R. Macedonia.

The External migration can be: emigration (eviction) and migration (Migrations). The focus here will be put before the emigration movements.

The wave of emigration, had always swept our country.

The first migrations date from long ago, from the time of Ottoman rule, the Balkan wars, the two world wars, till today. The mobility in space of the population of the Republic of Macedonia in the second half of the twentieth century is characterized by very large intensity. The volume, the guidelines and the types of these movements were primarily influenced by the dynamics of economic development, but also a significant impact had many other factors (demographic, social, political, etc.).

This paper use qualitative methods and descriptive research but also relevant statistical data.

\section{Data Sources on Migratory Movements from Republic of Macedonia}

The available data on migratory movements from Macedonia to abroad from domestic and foreign sources are very meager and insufficient for complete and real determining of its size and intensity.

The basic statistical and administrative data sources about migration in the country are: population censuses, records of the employment, documentation of the Ministry of Interior and the joint research of the the Statistical Office and the Ministry of Interior implemented in 1992 on the number of these persons evicted and migrated.

* It should be noted that data from population censuses do not represent the full scope of migration contingent, and do not provide relevant information on the dynamics of migratory movements.

* Information from employment services are concerning only on one part of population, and the data from the Ministry of Interior in the last decades, as vell the mentioned research on immigrant and evicted people do not reflect the real situation.

* As for the foreign data sources, until 1990's with them its hard to determine the number of displaced persons 
from the present day territory of the Republic of Macedonia because they in the are host countries are accounted on the basis of the former Yugoslav passports.

In the nineties only for the people who leave with Macedonian passports can be found information in some of the international data sources, so they do not necessarily represent the full scope of Macedonian citizens residing in different countries. Therefore, in terms of the lack of statistical data obtained by continuous monitoring of external migration, the predominant representation of immigration or migration can be defined indirectly by way of estimation.

\section{Classification of the Volume of Migration from Macedonia Abroad}

For the statistics it is important to monitor the volume and direction of movement of total Macedonian Diaspora. In terms of migratory movements the nineties stand as a special period that coincides with the independence of the Republic of Macedonia as sovereign state. It is a period of profound social and economic changes in the country, when there was a significant increase in the number of people who left the country and that led to increased migration potential.

According to the census of 1998 the number of migrants by the time spent abroad, suggested an increased intensity of these movements.

According to the state in 2002, the number of Macedonian citizens abroad amounts to 173611 people, of whome 50,000 people left in the period starting from the second half of the 1999 until the end of the first half of the 2004. In this period the country were 10,000 people per year on average.

In this context, it is illustrative the example of Switzerland where with the census are registered 27775 Macedonian citizens, according to data published in Bulletin of the Federal Bureau of foreigners in Switzerland in December 1998 the number of immigrants from the country is 50,982 people.

In the nineties in Macedonia is conducted a research about the evictions with which are gained statistical indicators for evicted-migrated persons, which includes people who have left the country. Within the labour force survey, conducted by the Institute for Statistics of the Republic of Macedonia in 1998 for the first time is included a questionnaire for people who have left the country. Their numbers in certain years is given in the following table:

\begin{tabular}{|l|l|l|l|l|l|l|l|l|c|}
\hline Year & 1990 & 1991 & 1992 & 1993 & 1994 & 1995 & 1996 & 1997 & 1998 \\
\hline Number of evicted & 7343 & 3.848 & 1,897 & 2.071 & 2.639 & 1.848 & 2528 & 2.578 & to April 422 \\
\hline
\end{tabular}

These data also indicate a tendency of increase of migratory movements in the nineties.

\section{Approximated Volume of Citizens of R. Macedonia who Nowadays Reside Abroad}

To approximate the total number of Macedonian citizens who reside abroad today we have to start from the knowledge provided by data of the population census from 2002, the data from other sources, domestic and foreign. According to the Council of Europe indicate that, according to the state in 1998/1999, the number of Macedonian citizens in just three European countries (Germany, Switzerland and Italy) is significantly higher than the overall number of migrants registered in the 1994 census. One should have in mind that today a relatively large number of our citizens resides in countries that emerged after the disintegration of Yugoslavia, and also in Sweden, Denmark, Australia, France, Holland, Belgium and others.

The total number of Macedonian citizens in the European countries could be approximated to 170,000 people. The number of our citizens overseas registered with census from 2002 is about 75,000 people. However, their inclusion in the this countries is very low, especially in North and South America. The made estimates of the total Macedonian Diaspora in overseas countries, as was pointed out previously, shows that today ranges from 500-550 thousand persons. Although is is difficult to differentiate migrants from the region of Macedonia, we believe that their participation in the total Macedonian Diaspora is actually $30.0 \%$.

Having in mind all these findings, as well as the numerous Macedonian colonies in the overseas countries where live and acting numerous citizens from various parts of $r$. Macedonia we can evaluate that this number is likely to double and move to $150-180000$ persons.

Upon the estimates for the European and overseas countries we can conclude that today outside of R. Macedonia are leaving between 320-350 thousands of its citizens.

In conditions of transformation of the temporary stay statuts of our citizens to their permanent resettlement abroad, as well as the process of intensifying the emigration more recently, it can be concluded that a significant part of the population of our country which resides outside the country is permanently lost or they its transformed in a greater extent into a static population and its marching progressively to a permanent loss of its ethno-cultural trait. 


\section{Regional Specificities of Migrational Movements}

One of the specifics of external migration of Macedonia is the manifested large differences in therms of the regional origins of the migrants. When it comes to regional aspects of the dynamics of the total number of Macedonian citizens abroad in the penultimate census period it is characteristical the emergence of a very large number of municipalities (17) which have above average intensity increase in the number of migrants $(72 \%)$. In all these communities is seen growth greater than 100.0\%, and which varies from 100.9\% (Ohrid) to 391.7\% (Radovish). The municipalities with the largest number of migrants in the country are represented in Graph 1.

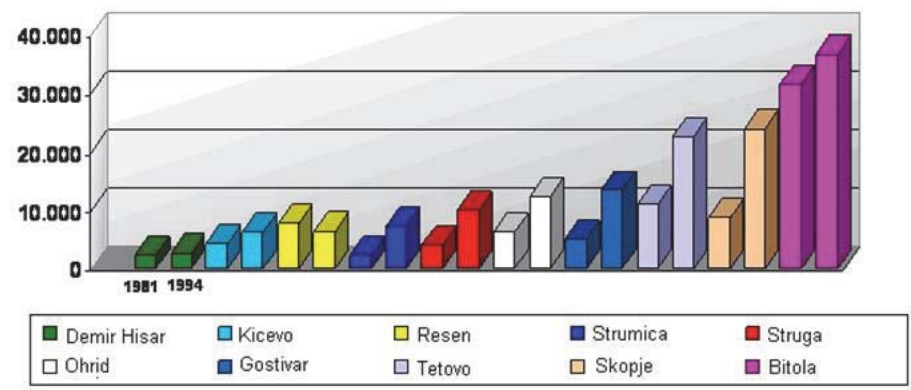

The comparison is made between the years 2001 and 2004. From Graph 2 can be noticed the growth of the number of migrants and that growth.

\subsection{The structure of migrants from urban and rural areas}

In terms of conditionality and the impact of external migration on the socioeconomic development of the country it is important to point out that in the period 2001-2004 the number of migrants from the urban settlements increased by $125.8 \%$ and from the villages $46,9 \%$. But despite this dynamic participation of migrants from rural areas in the total number of citizens abroad, according to the situation in 2004 was retained at a relatively high level. The comparison was made between the years 1981 and 1994. Since the subject of this paper is about the external migrations in Macedonia we will do a comparison of the data from the period when the country was in the SFR Yugoslavia (1981) and in the period when Macedonia is an independent country (1994).

\begin{tabular}{|l|c|c|c|c|}
\hline \multirow{2}{*}{} & \multicolumn{2}{|c|}{ Situation in numbers } & \multicolumn{2}{c|}{ Structure in\% } \\
\cline { 2 - 5 } & 1981 & 1994 & 1981 & 1994 \\
\hline Total citizens abroad & 100922 & 173611 & 100.0 & 100.0 \\
\hline -in urban settlements & 32173 & 72638 & 31.9 & 41.8 \\
\hline -in villages & 68746 & 100972 & 68.1 & 58.2 \\
\hline Citizens working abroad & 57964 & 87715 & 100.0 & 100.0 \\
\hline -in urban settlements & 18009 & 35756 & 311 & 40.8 \\
\hline -in villages & 39953 & 51959 & 68.9 & 59.2 \\
\hline \% Of citizens abroad & 5.3 & 8.3 & & \\
\hline -in urban settlements & 3.1 & 5.9 & & \\
\hline -in villages & 7.8 & 11.6 & & \\
\hline \% Of employees abroad of total active population & 7.2 & 10.1 & & \\
\hline -in urban settlements & 4.2 & 6.5 & & \\
\hline -in villages & 10.6 & 16.4 & & \\
\hline \% unemployed abroad in respect with all employed & 12.8 & 18.4 & & \\
\hline -in urban settlements & 5.4 & 10.0 & & \\
\hline -in villages & 33.1 & 44.1 & & \\
\hline
\end{tabular}

In the related period 1981-1994, the number of migrants from urban settlements has increased by $125.8 \%$ and from the rural settlements by $46.9 \%$. Even, despite such dynamic the participation of migrants from rural areas in the total of citizens who are abroad, according to the situation in 1994, retains the relatively high level (Graph 2). 


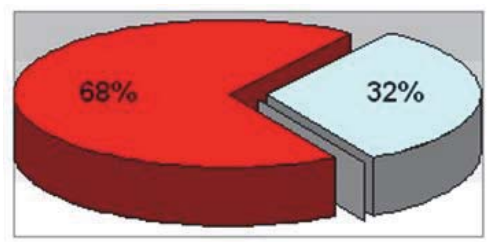

Year 1981
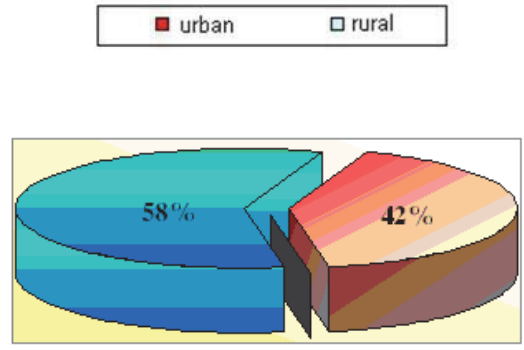

\section{Year 1994}

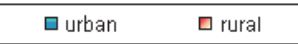

\section{Structural Characteristics of Migrants by the Demographic and Socioeconomic Traits}

The structural features of the citizens of Macedonia who live abroad are analyzed by gender and age structure, and by some socioeconomic characteristics, structures according to their national background, education and qualifications, activity and occupation. They are thoroughly observed on the country level, and within available data from the censuses of population and according to some prints are analyzed the conditions on regional scale.

\subsection{Structure by age}

The most important demographic mark is the composition of migration contingent by age, which leads to the vitality and the quality of the part of the population and labor force of the country. In the Table 2 are given data for citizens of Macedonia abroad by age.

Table 2

\begin{tabular}{|c|c|c|c|c|c|c|}
\hline \multirow{2}{*}{ Age } & \multicolumn{6}{|c|}{ Total } \\
\cline { 2 - 6 } & \multicolumn{2}{|c|}{ Number } & \multicolumn{2}{c|}{ Structure in\% } & \multicolumn{2}{c|}{$\%$ of total population } \\
\cline { 2 - 6 } & 2001 & 2004 & 2001 & 2004 & 2001 & 2004 \\
\hline Total & 100922 & 173610 & 100.0 & 100.0 & 5.3 & 8.3 \\
\hline $0-4$ & 11375 & 11212 & 11.3 & 6.5 & 5.9 & 6.9 \\
\hline $5-9$ & 10053 & 11610 & 10.0 & 6.7 & 5.4 & 6.7 \\
\hline $10-14$ & 5907 & 12758 & 5.9 & 7.4 & 3.3 & 7.1 \\
\hline $15-19$ & 4786 & 15353 & 4.7 & 8.8 & 2.7 & 8.7 \\
\hline $20-24$ & 7855 & 18168 & 7.8 & 10.5 & 4.5 & 10.8 \\
\hline $25-29$ & 13486 & 17226 & 13.4 & 9.9 & 8.2 & 10.4 \\
\hline $30-34$ & 15481 & 16217 & 15.3 & 9.3 & 10.7 & 10.0 \\
\hline $35-39$ & 9445 & 14735 & 9.4 & 8.5 & 8.3 & 9.3 \\
\hline $40-44$ & 7449 & 15694 & 7.4 & 9.0 & 6.6 & 10.4 \\
\hline $45-49$ & 5392 & 12215 & 5.3 & 7.0 & 4.8 & 10.1 \\
\hline $50-54$ & 3.351 & 8673 & 3.3 & 5.0 & 3.6 & 8.1 \\
\hline $55-59$ & 1.740 & 6591 & 1.7 & 3.8 & 2.3 & 6.5 \\
\hline $60-64$ & 709 & 4363 & 0.7 & 2.5 & 1.5 & 4.7 \\
\hline over 65 & 1.346 & 5.129 & 1.3 & 3.0 & 1.1 & 3.0 \\
\hline unknown & 2.547 & 3.669 & 2.5 & 2.1 & 56.1 & 54.3 \\
\hline
\end{tabular}


When structure of migrants is analyzed by its to age the generational migration coefficient is very important. It is calculated as a ratio between the contribution of the individual age groups in the total population and the share of persons of the same age in the total migrants.

The values of generational migration coefficient for year 2004 shows that unlike in the year 2001, in 2004 relatively less migrated the children from 0-9 years and significantly more the children from 10-14 years, then high school students and young people up to 24 years of age. In the same year relatively less migrated the persons in the age group from 3034 years as vell as the men from $35-44$ years.

For the migrants from 40 to 49 and those older than 50 years is typical tendency of a steady increase in their share in the total number of migrant workers, as a result of their prolonged stay sbroad.

For the traditional emigration areas is characteristic higher participation of older workers-migrants and for municipalities that had included later are more intense in the international migration flows, it is noticeable greater participation of persons aged from 25 to 39 years.

The structure by age and by indicators for the main contingents migrants, clearly points out to the conclusion that out of our country is situated very vital and qualitative part of its population. Therefore, these migratory movements have a significant impact on the demographic development of the Republic of Macedonia, especially on the biodynamics of its population-total and regional.

\subsection{Structure by nationality}

When is analyzed the scope and the dynamics of migrants according to the pleading of nationality also should be considered the incomplete coverage of Macedonians abroad, especially in non-European countries (Canada, US, Australia, New Zealand) where macednoans are present in large numbers. But, also the scope of migrants who belong to the Albanian nationality, according to many indications, can be assessed as incopmplete despite their main focus on European countries. But that suggests, for example, that the number of Macedonian citizens in Switzerland in December 1998 is 50982 people, of which about $80 \%$ are Albanians.

In terms of the active part of the migrational contingent to its national belongings it is noticable a variable volume and dynamics of workers-migrants. The participation of the Macedonians in the total number of migrant-workers in 1994 is $62.7 \%$. The participation of Albanians has grown for $29.5 \%$ and of Turks for $3.3 \%$, the participation of Roma oscillates. The biggest change came in people who are staying as family members. Fot the Albanians is observed absolute growth (index 385.2). The participation of Albanians in total migration increases and the participation of Turks and Roma decreases.

Should be emphasized that the structure of the citizens of Macedonia abroad by their national plea from certain municipalities correspond with the national structure of the population. The biggest part of Albanian migrants come from Nort-west part of Macedonia, Tetovo and Gostivar and less from Skopje.

The participation of the Roma nationality is at most from Skopje especially from the municipality of Chair.

The analysis of the available data for Macedonian nationals abroad under hallmarks nationality, shows that vrememski in the observed time interval is noticanle a tendency of constant growth of migrants from the Albanian nationality. That can be seen from the Table 3

\begin{tabular}{|c|c|c|c|c|c|c|c|c|c|c|c|}
\hline year & Total & Maced. & Alban. & Turks & Roma & Muslis & Serbs & Vlachs & Other nationalities & Non stated & Unknown \\
\hline 1981 & 100922 & 64794 & 22340 & 4238 & 2526 & 1871 & 1138 & 257 & 1234 & 748 & 1776 \\
\hline 1994 & 174974 & 109334 & 51556 & 5689 & 3.926 & 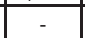 & 827 & 142 & 2,842 & 369 & - \\
\hline \multicolumn{12}{|c|}{ Indices } \\
\hline $1994 / 81$ & 173.2 & 168.7 & 231.3 & 134.2 & 155.4 & - & 72.7 & 55.3 & 230.3 & 49.3 & - \\
\hline \multicolumn{12}{|c|}{ Structure in\% } \\
\hline 1981 & 100.0 & 64.2 & 22.1 & 4.2 & 2.5 & 1.9 & 1.1 & 0.3 & 1.2 & 0.7 & 1.8 \\
\hline 1994 & 100.0 & 62.2 & 29.6 & 3.2 & 2.2 & - & 0.5 & 0.1 & 1.6 & 0.2 & - \\
\hline \multicolumn{12}{|c|}{ Participation in (\%) of citizens abroad in the total population of a particular nationality } \\
\hline 1981 & 5.3 & 5.1 & 5.9 & 4.9 & 5.9 & 4.7 & 2.6 & 4.0 & 9.5 & 4.8 & 46.4 \\
\hline 1994 & 8.3 & 7.8 & 10.7 & 6.9 & 8.3 & - & 2.0 & 1.6 & 7.3 & 16.9 & - \\
\hline \multicolumn{12}{|c|}{ Employees abroad } \\
\hline 1981 & 57964 & 34905 & 15648 & 2.388 & 1.164 & 1.129 & 762 & 154 & 713 & 365 & 737 \\
\hline 1994 & 87715 & 54995 & 25888 & 2.922 & 1.474 & - & 551 & 89 & 1661 & 175 & - \\
\hline
\end{tabular}




\begin{tabular}{|c|c|c|c|c|c|c|c|c|c|c|c|c|c|}
\hline \multicolumn{10}{|c|}{ Indices } \\
\hline $1994 / 81$ & 151.3 & 157.4 & 165.4 & 122.4 & 126.6 & - & 72.3 & 57.8 & 233.0 & 47.9 & - \\
\hline \multicolumn{10}{|c|}{ Structure (\%) } \\
\hline 1981 & 100.0 & 60.2 & 27.0 & 4.1 & 2.0 & 2.0 & 1.3 & 0.3 & 1.2 & 0.6 & 1.3 \\
\hline 1994 & 100.0 & 62.7 & 29.5 & 3.3 & 1.7 & - & 0.6 & 0.1 & 1.9 & 0.2 & - \\
\hline \multicolumn{10}{|c|}{} \\
\hline 1994 & 87089 & 54,379 & 25777 & 2.767 & 2452 & - & 276 & 53 & 1.181 & 194 & - \\
\hline \multicolumn{10}{|c|}{ Indices } \\
\hline $1994 / 81$ & 202.7 & 181.9 & 385.2 & 149.6 & 180.0 & - & 73.4 & 51.5 & 226.7 & 50.7 & - \\
\hline \multicolumn{10}{|c|}{ - } \\
\hline 1981 & 100.0 & 69.6 & 15.6 & 4.3 & 3.2 & 1.7 & 0.9 & 0.2 & 1.2 & 0.9 & 2.4 \\
\hline 1994 & 100.0 & 62.4 & 29.6 & 3.2 & 2.8 & - & 0.3 & 0.1 & 1.4 & 0.2 & - \\
\hline \multicolumn{10}{|c|}{ Share (in\%) of family members in the total number of citizens abroad } \\
\hline 1981 & 42.6 & 46.1 & 30.0 & 43.7 & 53.9 & 39.7 & 33.0 & 40.1 & 42.2 & 51.2 & 58.5 \\
\hline 1994 & 49.8 & 49.7 & 49.9 & 48.6 & 62.5 & - & 33.4 & 37.3 & 41.6 & 52.6 & - \\
\hline
\end{tabular}

\section{Duration of Stay of Macedonian Citizens Abroad}

Experience has shown that a rear the cases when someone went had find a job and then he get back home. We can say that the stay of Macedonian citizens abroad is long and in large numbers and in many case is for a lifetime and migrations from temporary are turning to permanent.

This is confirmed and can be seen from the conducted censuses. We have data from population Census from 1994. The results are presented graphically and can be seen in Graph 3.

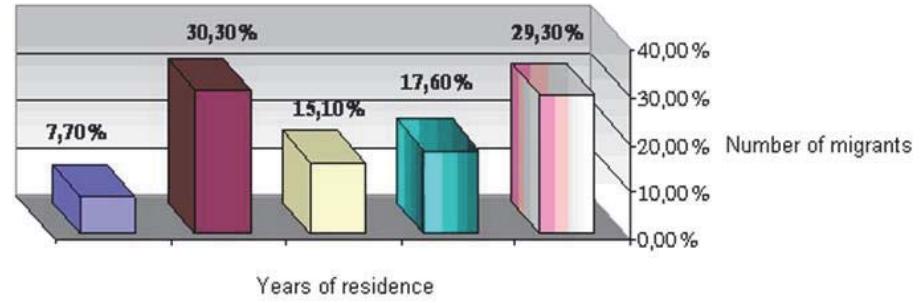

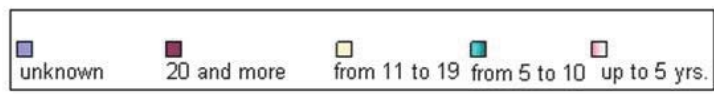

Less than half of the total number of migrants registered with the census reside abroad up to 10 years. The proportion of citizens who reside abroad 20-24 years and 25 years and more is very big because their share in the total migration is close to one-third. It is important to point out the length of the duration of stay of Macedonian migrants abroad in certain areas. The proportion of migrants abroad from 5 to 10 years is particularly large in this municipalities: Gostivar, Krusevo, Kumanovo, Ohrid, Strumica and Tetovo, and their share in the total number of migrants is a fifth or more.

Oround $70.1 \%$ of migrants residing abroad up to one year accounts of emigrational municipalities Gostivar, Kicevo, Struga and Tetovo area of the City.

Almost half (49.5\%) of those who are abroad from one to four years originate from Gostivar, Tetovo and Skopje and on them and on municipality of Bitola belongs $57.9 \%$ of migrants who are abroad from 510 years. In other monitored intervals of residence (11-15; 16-19; $2024 ; 25$ years and beyond) the largest share in the total number of migrants has municipality of Bitola where it has respectively $27.8 \%, 30.7 \%, 35.1 \%, 40.3 \%$ of the share. Other municipalities with higher participation are Skopje, Ohrid, Prilep, Resen and Tetovo.

For the traditional emigration areas like Resen, Bitola and Demir Hisar is characteristic very high representation of migrant-workers who are abroad 20 years and more. Their share in the total number of persons working abroad reaches three quarters. The participation of persons who are staying abroad for more than two decades as a family members is significantly smaller and is slightly higher than one third.

The analysis of the duration of the stay of Macedonian citizens abroad on very illustrative way shows trends and changes in scope and intensity of these movements in the regional context, especially among traditional emigrational 
regions and municipalities of emigration- The western part of Macedonia.

The Volume, dynamics and main features of the returnees from abroad

The determination of the scope of macedonian citizens who are returning from abroad is very difficult because they do not report themselves to the competent authorities, and any information about their reducing in individual countries of reception does not always return to the country. Censuses of Population represent almost the only source of information on the number and structure of returnees from abroad.

We have data from the population census of 1984 and 1994 the number of migrants who have returned from temporary work and from their stay abroad. From the data can be concluded that the reversible migration movements have tends to decrease.

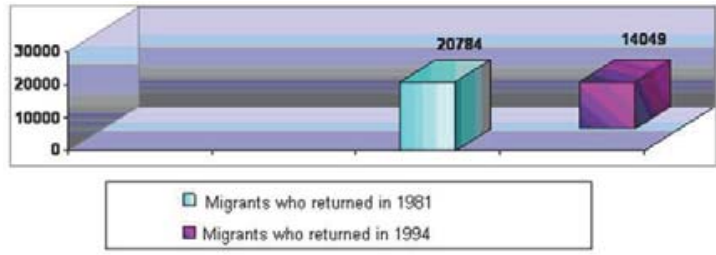

\section{Graph 4}

In comparison with the structure by occupation before going to work abroad these data show that the most of the returnees who formerly practiced agriculture are employed in non-agricultural activities. The employment in nonagricultural activities, among other things, is motivated by experience that has been gained in abroad. The analysis of the volume, dynamics and characteristics of returnees from abroad on the basis of the available data suggest that the volume of returnees from abroad decreases.

The latest empirical researches on migration in Macedoni on population and labor force who is outside the country show very significant changes that have occurred in their structure by sex, because of the increase in the number of family members.

The scope and dynamics, as well as the participation of men and women in the total number of migrants record different trends and conditions.

From the conducted researches and the made survey on about of fifty participants for their migration in a foreign country and in the future, I came to the following conclusions:

The survey was conducted on 50 subjects from Southeast Macedonia who emanate from the areas where the trend of migration is particularly pronounced in the Macedonian population to the United States and the countries of the European Community.

The purpose of the research is to determine how many of the male respondents, and respectively from female population is willing to migrate abroad, particularly in the United States and the countries of the European Community and to stay longer than one year.

Considering the purpose and the object of the research I did $X^{2}$ (Chi-square) test with which we tested the hypothesis which states:

- The number of male and female respondents who are willing to migrate to the United States is no different from the number of respondents of either sex who are willing to migrate within the European Community so in the future to stay there longer than one year.

The male and female respondents were asked two questions in the survey on which they should give honest answered:

1. Are You ready to migrate to the United States and to stay there longer than a year?

2. Are You ready to migrate in the countries of the European Community and to stay there longer than a year?

- Male and female respondents answered the questions with yes and no and their answers are presented in Tables 1 and 2. The data processed with the help of chi-square test. In addition are given the calculations made for the value of the chi-square test, in terms of both issues.

\begin{tabular}{|c|c|c|c|}
\hline & Yes & No & Total \\
\hline Migration to US & 23 & 27 & 50 \\
\hline Migration to the countries of the European Community & 30 & 20 & 50 \\
\hline Total & 53 & 47 & 100 \\
\hline
\end{tabular}


From the obtained results we can apply the $\mathrm{X} 2$ test on the following table:

\begin{tabular}{|c|c|c|c|c|}
\hline $\mathrm{F} 0$ & $\mathrm{Ft}$ & $\mathrm{F} 0-\mathrm{F} \mathrm{t}$ & $(\mathrm{Fo}-\mathrm{F} \mathrm{t})^{2}$ & $(\mathrm{Fo}-\mathrm{F} \mathrm{t})^{2} \mathrm{~F}_{0}$ \\
\hline 23 & 26.5 & -3.5 & $12: 25$ & 0.46 \\
\hline 27 & 235 & 3.5 & $12: 25$ & 0.5 \\
\hline 30 & 265 & 3.5 & $12: 25$ & $00: 46$ \\
\hline 20 & 235 & -3.5 & $12: 25$ & 0.5 \\
\hline & & & & $\Sigma=1.92$ \\
\hline
\end{tabular}

The value of the resultant chi square $(1,92)$, which is small and shows us that there are differences in the willingness of male and female respondents to migrate to the United States and the countries of the European Community for a period longer than one year. By that is accepted the previously set zero hypothesis of the research.

The results of the research shows that the number of male and female respondents - $53 \%$, who are ready to move ( migrate ) in the US and countries of the European Community for more than a year is bigger for a period longer than one year. But greater percentage of respondents who would have migrated within the European community (30\%) while the number of people who would have migrated to the United States is lower - $23 \%$. Also worries the fact that the growing number of intellectuals intend to migrate that shows that in the future will be a greater number of graduated highly educated cadres (some call that ,, brain drain") that will migrate in the future to the United States or the EU. Those are mostly young people and that will have effect of aging on the country because most often young people for various reasons: economic, social, political and other reasons left and only a small part of those who leave are back in the country.

\section{Conclusion}

From the sources at our disposal and the results of the research we can say that the external migration in the transition period to the present in the Republic of Macedonia is in constant growth.

Migration as a phenomenon is a negative thing for the country and causes many negative effects (aging of society, brain drain).

With increasing number of migrants there is a forthcoming danger of depopulation of the population. The danger lies in the fact that, a growing number of young and educated intellectuals who migrate abroad in search for work that can not be found in R. Macedonia. Therefore, the outflow of intellectual staff from Macedonia is a separate issue that needs to put on special focus and to be undertaken preventive measures by the country structures itself to prevent this occurrence.

There is a growing number of people who go out of state, and very few of those back. It shows that temporary migration often turn into migration of permanent character.

We believe that the people go abroad for a variety of economic, social, and other political reasons and most of those who leave do not come back. That means that living conditions somewhere outside the borders the home country are better than in Macedonia and that there is a danger of increasing in the number of migrants, especially now, when the Republic of Macedonia faces with high unemployment, economic crisis and political instability caused by internal and external factors, but far most from the neighbors who do not want Macedonia to join the family of European countries and do not recognize the constitutional name and national identity and historical continuity of our country.

\section{References}

Council of Europe (1999), Recent Demographic Developments in Europe 1999, September, p. 538

Agency of Emigration,(1999) Emigration from Republic of Macedonia-information, Skopje, p. 10.

Dimitriev Elka, Janeska Verica, Hinik Branko (1998) Migration mouvments (exsternal and internal) and regional distribution of population on R.Macedonia.

Informacion from the agency for statistics on R.Macedonia , Statistical yearbook "View and studies", No. 88 , Skopie, p.1-24.

Agency for statistics on R.Macedonia, Projections of the Population of the Republic of Macedonia for 2020 by age and sex, exspert team, Skopie,p.300.

Stevan Aleksoski, Faculty of law on University of Goce Delcev- Stip,( 2013) Exploring the views of student youth about external migration in the R.Macedonia. 